\title{
Solubility of Benzil in Binary Alkane + Methyl tert-Butyl Ether Solvent Mixtures
}

\author{
Mary E. R. McHale, J oyce R. Powell, Ann-Sofi M. Kauppila, and William E. Acree, J r.* \\ Department of Chemistry, University of North Texas, Denton, Texas 76203-0068
}

\begin{abstract}
Experimental solubilities are reported for benzil (1,2-diphenylethanedione) dissolved in six binary mixtures containing methyl tert-butyl ether with hexane, heptane, octane, cyclohexane, methylcyclohexane and 2,2,4-trimethylpentane at $25^{\circ} \mathrm{C}$. Results of these measurements are used to test two mathematical representations based upon the combined nearly ideal binary solvent (NIBS)/Redlich-Kister equation and modified Wilson model. For the six systems studied, the combined NIBS/Redlich-Kister equation was found to provide the more accurate mathematical representation of the experimental data, with an overall average absolute deviation between measured and calculated values being on the order of $0.3 \%$. Slightly larger deviations were noted in the case of the modified Wilson equation.
\end{abstract}

\section{Introduction}

Solid-liquid equilibrium data of organic nonelectrolyte systems are becoming increasingly important in the petroleum industry, particularly in light of present trends toward heavier feedstocks and the known carcinogenicity/ mutagenicity of many of the larger polycyclic aromatic compounds. Solubility data for a number of polycyclic aromatic hydrocarbons (i.e, anthracene and pyrene) and heteroatom polynudear aromatics (i.e., carbazole, dibenzothiophene, and xanthene) have been published in the recent chemical literature (for listing of references see: Acree, 1994, 1995a,b). Despite efforts by experimental ists and scientific organizations, in terms of both new experimental measurements and critically-evaluated data compilations, there still exist numerous systems for which solubility data are not readily available.

To address this problem, researchers have turned to group contribution methods and semiempirical expressions to predict desired quantities. Group contribution methods have proved fairly successful in estimating solid solubility in pure and binary solvent mixtures from structural information. Practical application though, is limited to systems for which all group interaction parameters are known. Interaction parameters can be evaluated from liquid-vapor, liquid-liquid, and solid-liquid equilibria data. It is important that the data base contains as many different functional groups as possible, preferably with adequate representation from both mono- and multifunctional solute/solvent molecules to permit evaluation of potential synergistic effects. The data base should contain sufficient experimental values near infinite dilution in the event that one wishes to determine separate interaction parameters for finite concentration and infinite dilution activity coefficient predictions.

Continued devel opment of solution models for describing the thermodynamic properties of a solute in binary solvent systems requires that a large data base be available for assessing the applications and limitations of derived expressions. Currently, only a limited data base exists for crystalline nonelectrolyte solubility in binary solvent mixtures. Few aromatic solutes listed in the data base contain an aldehyde or ketone functional group. For this reason, benzil (1,2-diphenylethanedione) solubilities were deter-

* To whom correspondence should be addressed. E-mail: acree@cas1. unt.edu. mined in six binary alkane + methyl tert-butyl ether solvent mixtures. Results of these measurements are used to further test the descriptiveabilities of several previously derived expressions.

\section{Experimental Methods}

Benzil (Aldrich $98+\%$ ) was recrystallized three times from methanol. Cyclohexane (Aldrich, HPLC), hexane (Aldrich, 99\%), heptane (Aldrich, HPLC), octane (Aldrich, 99+\%, anhydrous), methylcyclohexane (Aldrich, 99+\%, anhydrous), 2,2,4-trimethyl pentane (Aldrich, HPLC), and methyl tert-butyl ether (Arco, 99.9+\%) were stored over molecular sieves before being fractionally distilled. Gas chromatographic analysis showed solvent purities to be $99.7 \mathrm{~mol} \%$ or better. Binary solvent mixtures were prepared by mass so that compositions could be calculated to 0.0001 mole fraction.

Excess solute and solvent were placed in amber glass bottles and allowed to equilibrate in a constant temperature water bath at $(25.0 \pm 0.1){ }^{\circ} \mathrm{C}$ for at least 3 days (often longer). Attainment of equilibrium was verified both by repetitive measurements after a minimum of 3 additional days and by approaching equilibrium from supersaturation by preequilibrating the solutions at a higher temperature. Aliquots of saturated benzil solutions were transferred through a coarse filter into a tared volumetric flask to determine the amount of sample and diluted quantitatively with methanol for spectrophotometric analysis at $390 \mathrm{~nm}$ (Acree and Bertrand, 1983) on a Bausch and Lomb Spectronic 2000. Concentrations of the dilute solutions were determined from a Beer-Lambert law absorbance versus concentration working curve derived from measured absorbances of nine standard solutions of known molar concentrations ranging from $\mathrm{C} / \mathrm{mol} \mathrm{L}^{-1}=4.30 \times 10^{-3}$ to $\mathrm{C} / \mathrm{mol} \mathrm{L}^{-1}=2.15 \times 10^{-2}$. The cal culated molar absorptivity of $\epsilon / \mathrm{L} \mathrm{mol}^{-1} \mathrm{~cm}^{-1}=65.8$ was constant over the concentration range. Experimental benzil solubilities in the six binary alkane + methyl tert-butyl ether solvent mixtures studied are listed in Table 1. Numerical values represent the average of between four and eight independent determinations, with the measured values being reproducible to within $\pm 1.5 \%$. Measured mole fraction solubilities in the pure alkane solvents are in excellent agreement with published literature values (Acree and Rytting, 1982; Acree and Bertrand, 1983; Acree and Procyk, 1988). 
J ournal of Chemical and Enginering Data, Vol. 41, No. 5, 19961185

Table 1. Experimental Mole Fraction Solubilities of Benzil $\left(x_{A}^{\text {sat }}\right)$ in Binary Alkane (B) + Methyl tert-Butyl Ether (C) Solvent Mixtures at $25.0^{\circ} \mathrm{C}$

\begin{tabular}{|c|c|c|c|}
\hline $\mathrm{x}_{\mathrm{C}}^{0}$ & $x_{A}^{\text {sat }}$ & $x_{C}^{0}$ & $x_{A}^{\text {sat }}$ \\
\hline \multicolumn{4}{|c|}{ Hexane (B) + Methyl tert-Butyl Ether (C) } \\
\hline 0.0000 & 0.00575 & 0.6191 & 0.02911 \\
\hline 0.1195 & 0.00840 & 0.8209 & 0.04558 \\
\hline 0.2112 & 0.01073 & 0.8934 & 0.05310 \\
\hline 0.4046 & 0.01758 & 1.0000 & 0.06496 \\
\hline 0.5247 & 0.02349 & & \\
\hline \multicolumn{4}{|c|}{ Heptane (B) + Methyl tert-Butyl Ether (C) } \\
\hline 0.0000 & 0.00656 & 0.6517 & 0.03015 \\
\hline 0.1289 & 0.00917 & 0.8367 & 0.04589 \\
\hline 0.2260 & 0.01146 & 0.9187 & 0.05502 \\
\hline 0.4455 & 0.01887 & 1.0000 & 0.06496 \\
\hline 0.5480 & 0.02359 & & \\
\hline \multicolumn{4}{|c|}{ Octane (B) + Methyl tert-Butyl Ether (C) } \\
\hline 0.0000 & 0.00724 & 0.6705 & 0.03088 \\
\hline 0.1332 & 0.00987 & 0.8413 & 0.04496 \\
\hline 0.2605 & 0.01315 & 0.9170 & 0.05342 \\
\hline 0.4808 & 0.02098 & 1.0000 & 0.06496 \\
\hline 0.5679 & 0.02489 & & \\
\hline \multicolumn{4}{|c|}{ Cyclohexane (B) + Methyl tert-Butyl Ether (C) } \\
\hline 0.0000 & 0.01071 & 0.5759 & 0.04033 \\
\hline 0.0955 & 0.01457 & 0.7876 & 0.05313 \\
\hline 0.1884 & 0.01903 & 0.8915 & 0.05897 \\
\hline 0.3748 & 0.02941 & 1.0000 & 0.06496 \\
\hline 0.4677 & 0.03419 & & \\
\hline \multicolumn{4}{|c|}{ Methylcyclohexane (B) + Methyl tert-Butyl Ether (C) } \\
\hline 0.0000 & 0.01128 & 0.6153 & 0.03887 \\
\hline 0.0982 & 0.01405 & 0.8112 & 0.05205 \\
\hline 0.1988 & 0.01758 & 0.9116 & 0.05909 \\
\hline 0.4158 & 0.02746 & 1.0000 & 0.06496 \\
\hline 0.5146 & 0.03277 & & \\
\hline \multicolumn{4}{|c|}{ 2,2,4-Trimethylpentane $(B)+$ Methyl tert-Butyl Ether $(C)$} \\
\hline 0.0000 & 0.00589 & 0.6801 & 0.02960 \\
\hline 0.1325 & 0.00795 & 0.8490 & 0.04483 \\
\hline 0.2586 & 0.01065 & 0.9233 & 0.05382 \\
\hline 0.4790 & 0.01811 & 1.0000 & 0.06496 \\
\hline 0.5772 & 0.02298 & & \\
\hline
\end{tabular}

\section{Results and Discussion}

Acree and co-workers (Acree and Zvaigzne, 1991; Acree et al., 1991; Acree, 1992) suggested possible mathematical representations for isothermal solubility data based upon either a combined NIBS/Redlich-Kister model

$$
\ln x_{A}^{\text {sat }}=x_{B}^{0} \ln \left(x_{A}^{\text {sat }}\right)_{B}+x_{C}^{0} \ln \left(x_{A}^{\text {sat }}\right)_{C}+x_{B}^{0} x_{C}^{0} \sum_{i=0}^{N} S_{i}\left(x_{B}^{o}-x_{C}^{0}\right)^{i}
$$

or modified Wilson equation (Comer and Kopecni, 1990)

$$
\begin{aligned}
& \ln \left[a_{A}(s) / x_{A}^{s a t}\right]=1-x_{B}^{o}\left\{1-\ln \left[a_{A}(s) /\left(x_{A}^{s a t}\right)_{B}\right]\right\} / \\
& \quad\left(x_{B}^{0}+x_{C}^{o} \Lambda_{B C}^{\text {adj }}\right)-x_{C}^{0}\left\{1-\ln \left[a_{A}(s) /\left(x_{A}^{s a t}\right)_{C}\right]\right\} /\left(x_{B}^{o} \Lambda_{C B}^{\text {adj }}+x_{C}^{o}\right)
\end{aligned}
$$

where the various $S_{i}$ and $\Lambda_{i j}^{\text {adj }}$ "curve-fit" parameters can be evaluated via least squares analysis. In eqs 1 and 2 $x_{B}^{0}$ and $x_{C}^{0}$ refer to the initial mole fraction composition of the binary solvent calculated as if the solute were not present, $a_{A}(s)$ is the activity of the solid solute, and $\left(x_{A}^{\text {sat }}\right)_{i}$ is the saturated mole fraction solubility of the solute in pure solvent $i$. The numerical value of $a_{A}(s)=0.224$ (Acree and Bertrand, 1983) used in the modified Wilson computations was calculated from

$$
\text { In } \mathrm{a}_{\mathrm{A}}(\mathrm{s})=-\Delta_{\text {fus }} \mathrm{H}_{\mathrm{A}}\left(\mathrm{T}_{\mathrm{mp}}-\mathrm{T}\right) /\left(\mathrm{RTT} \mathrm{T}_{\mathrm{mp}}\right)
$$

the molar enthalpy of fusion, $\Delta_{\text {fus }} \mathrm{H}_{\mathrm{A}} / \mathrm{mol} \mathrm{mo}^{-1}=19480$

\begin{tabular}{|c|c|c|c|c|}
\hline \multirow[b]{2}{*}{$\begin{array}{l}\text { binary solvent system } \\
\text { component }(B)+\text { component }(C)\end{array}$} & \multicolumn{2}{|c|}{ eq 1} & \multicolumn{2}{|c|}{ eq 2} \\
\hline & $\mathrm{S}_{\mathrm{i}}^{\mathrm{a}}$ & $\begin{array}{c}\% \\
\operatorname{dev}^{b}\end{array}$ & $\Lambda_{\mathrm{ij}}^{\mathrm{adj}, \mathrm{c}}$ & $\begin{array}{c}\% \\
\mathrm{dev}^{\mathrm{b}}\end{array}$ \\
\hline hexane + methyl tert-butyl ether & $\begin{array}{l}0.522 \\
0.149 \\
0.317\end{array}$ & 0.4 & $\begin{array}{l}1.253 \\
0.830\end{array}$ & 0.9 \\
\hline heptane + methyl tert-butyl ether & $\begin{array}{l}0.115 \\
0.073 \\
0.307\end{array}$ & 0.2 & $\begin{array}{l}1.060 \\
0.980\end{array}$ & 1.0 \\
\hline octane + methyl tert-butyl ether & $\begin{array}{l}0.003 \\
0.225\end{array}$ & 0.3 & $\begin{array}{l}0.970 \\
1.144\end{array}$ & 1.6 \\
\hline $\begin{array}{l}\text { cyclohexane + methyl tert-butyl } \\
\text { ether }\end{array}$ & $\begin{array}{l}1.286 \\
0.362 \\
0.012\end{array}$ & 0.6 & $\begin{array}{l}2.333 \\
0.158\end{array}$ & 0.4 \\
\hline $\begin{array}{l}\text { methylcyclohexane }+ \text { methyl } \\
\text { tert-butyl ether }\end{array}$ & $\begin{array}{r}0.667 \\
-0.111 \\
-0.037\end{array}$ & 0.2 & $\begin{array}{l}1.260 \\
2.536\end{array}$ & 0.3 \\
\hline $\begin{array}{l}\text { 2,2,4-trimethylpentane }+ \\
\text { methyl tert-butyl ether }\end{array}$ & $\begin{array}{l}-0.111 \\
-0.066\end{array}$ & 0.1 & $\begin{array}{l}1.028 \\
0.448\end{array}$ & 0.1 \\
\hline
\end{tabular}

Table 2. Mathematical Representation of Benzil Solubilities in Several Binary Alkane (B) + Methyl tert-Butyl Ether (C) Solvent Mixtures

a Combined NIBS/Redlich-Kister curve-fit parameters are ordered as $S_{0}, S_{1}$, and $S_{2} .{ }^{b}$ Deviation $(\%)=(100 / 7) \sum \mid\left[\left(x_{A}^{\text {sat }}\right)_{i}^{\text {calc }}-\right.$ $\left.\left(x_{A}^{\text {sat }}\right)_{i}^{\text {exp }}\right] /\left(x_{A}^{\text {sat }}\right)_{i}^{\text {exp }} \mid$. ' ${ }^{c}$ Adjustable parameters for the modified Wilson equation are ordered as $\Lambda_{\mathrm{BC}}^{\text {adj }}$ and $\Lambda_{\mathrm{CB}}^{\text {adj }}$.

(Weast, 1971), at the normal melting point temperature of the solute, $T_{\mathrm{mp}} / \mathrm{K}=368.3$.

The ability of eqs 1 and 2 to mathematically represent the experimental solubility of benzil in the six binary alkane + methyl tert-butyl ether solvent systems is summarized in Table 2 in the form of "curve-fit" parameters and percent deviations in back-calculated solubilities. Careful examination of Table 2 reveals that both equations provide an accurate mathematical representation for how the solubility of benzil varies with solvent composition. For the six benzil systems studied, the combined NIBS/RedlichKister equation was found to provide the more accurate mathematical representation of the experimental data, with an overall average absolute deviation between measured and calculated values being on the order of $0.3 \%$. Slightly larger deviations were noted in the case of the modified Wilson equation.

From a computational standpoint, eq 1 will likely be preferred because the expression contains provisions for the inclusion of additional coefficients as might be needed to mathematically describe the experimental data. Most research groups involved in reporting thermodynamic properties have computer programs for evaluating the Redlich-Kister coefficients. With this idea in mind, we recommend that the future presentation of experimental isothermal solubility data for slightly soluble solid solutes dissolved in binary solvent mixtures include a tabulation of the actual observed values and, if possible, that the solubility data be mathematically represented by eq 1 . Realizing that a single equation will not be applicable to all systems encountered, we further suggest eq 2 as an alternative mathematical representation for systems having extremely large solubility ranges and/or highly asymmetrical In $x_{A}^{\text {sat }}$ versus $x_{B}^{0}$ curves, such as the carbazole + alkane + tetrahydropyran systems reported previously (Acree et al., 1991).

\section{Literature Cited}

Acree, W. E., I r. Mathematical Representation of Thermodynamic Properties. Part 2. Derivation of the Combined N early I deal Binary Solvent (NIBS)/Redlich-Kister Mathematical Representation from a Two-Body and Three-Body Interactional Mixing Model. Thermochim. Acta 1992, 198, 71-79. 
Acree, W. E., J r. Polycyclic Aromatic Hydrocarbons in Pureand Binary Solvents; Volume 54 in IUPAC Solubility Data Series; Oxford University Press: Oxford, United Kingdom, 1994.

Acree, W. E., J r. Polycydic Aromatic Hydrocarbons: Binary Nonaque ous Systems: Part 1 (Solutes A-E); Volume 58 in IUPAC Solubility Data Series; Oxford University Press: Oxford, United Kingdom, $1995 a$.

Acree, W. E., J r. Polycyclic Aromatic Hydrocarbons: Binary Nonaque ous Systems: Part 2 (Solutes F-Z); Volume 59 in IUPAC Solubility Data Series; Oxford University Press: Oxford, United Kingdom, $1995 b$.

Acree, W. E., J r.; Rytting, J . H. Solubility in Binary Solvent Systems. I: Specific Versus Nonspecific Interactions. J. Pharm. Sci. 1982 71, 201-205.

Acree, W. E., J r.; Bertrand, G. L. Thermochemical Investigations of Nearly I deal Binary Solvents. 6. Solubilities of I odine and Benzil in Systems of Nonspecific Interactions. J . Solution Chem. 1983, 12, 101-113.

Acree, W. E., J r.; Procyk, A. D. Comment on Entropies of Diphenylglyoxal Solutions in Non-polar Solvents. Thermochim. Acta 1988, 130, 367-368.
Acree, W. E., J r.; Zvaigzne, A. I. Thermodynamic Properties of Nonelectrolyte Solutions. Part 4. Estimation and Mathematical Representation of Solute Activity Coefficients and Solubilities in Binary Solvents Using the NIBS and Modified Wilson Equations. Thermochim. Acta 1991, 178, 151-167.

Acree, W. E., J r.; McCargar, J. W.; Zvaigzne, A. I.; Teng, I.-L. Mathematical Representation of Thermodynamic Properties. Carbazole Solubilities in Binary Alkane + Dibutyl Ether and Alkane + Tetrahydropyran Solvent Mixtures. Phys. Chem. Liq. 1991, 23, 27-35.

Comer, J . F .; Kopecni, M. M. Prediction of Gas Chromatography Solute Activity Coefficients in Mixed Stationary Phases Based on the Wilson Equation. Anal. Chem. 1990, 62, 991-994.

Weast, R. C., Ed. CRC Handbook of Chemistry and Physics, 52nd ed.; CRC Press: Cleveland, $\mathrm{OH}, 1971$.

Received for review April 25, 1996. Accepted J une 23, 1996. ${ }^{\otimes}$

J E 960149]

${ }^{\otimes}$ Abstract published in Advance ACS Abstracts, August 1, 1996. 